\title{
Linaclotide: evidence for its potential use in irritable bowel syndrome and chronic constipation
}

This article was published in the following Dove Press journal:

Core Evidence

23 June 2012

Number of times this article has been viewed

Noel Lee

Arnold Wald

Division of Gastroenterology and Hepatology, University of Wisconsin School of Medicine and Public Health, Madison, WI, USA
Correspondence: Arnold Wald Division of Gastroenterology and Hepatology, University of Wisconsin School of Medicine and Public Health, Centennial Building, 4th floor, I 685 Highland Avenue, Madison, WI 53705, USA

Tel + I 6082631995

$\mathrm{Fax}+\mathrm{I} 6082655677$

Email axw@medicine.wisc.edu
Abstract: Both irritable bowel syndrome (IBS), characterized by chronic and recurrent abdominal pain and altered bowel habits, and functional constipation are highly prevalent gastrointestinal problems for which many patients seek medical advice. A diverse number of treatment approaches are currently recommended to treat persons with chronic constipation as well as patients with IBS in which constipation is the main gastrointestinal symptom (IBS-C). These approaches have had somewhat limited success, and many patients remain dissatisfied with available therapy. Recently, linaclotide, a novel intestinal secretagogue, which works by activating the guanylate cyclase $\mathrm{C}$ receptor on the luminal surface of the intestinal epithelium, has been demonstrated to be efficacious in patients with both chronic functional constipation and with IBS-C in a series of randomized, placebo-controlled studies in these populations. Evidence for this assertion is provided in this systematic review of the pharmacologic properties of this novel agent and the published pivotal studies which support the efficacy of this agent in targeted populations.

Keywords: linaclotide, constipation, irritable bowel syndrome, safety, efficacy

Core evidence clinical impact summary for linaclotide in chronic constipation (CC) and irritable bowel syndrome (IBS)

\begin{tabular}{|c|c|c|}
\hline Outcome measure & Evidence & Implications \\
\hline Disease oriented evidence & Randomized clinical trials & \\
\hline \multirow[t]{2}{*}{ Response rate } & Ref I6 (CC) & Safe and effective but only $10 \%-20 \%$ \\
\hline & Ref I9,20 (IBS) & above placebo responses \\
\hline \multirow[t]{2}{*}{ Improvement in QOL } & Ref I6 (CC) & Improvement significantly greater than \\
\hline & Ref 2 I (IBS) & placebo \\
\hline \multicolumn{3}{|l|}{ Patient oriented evidence } \\
\hline \multirow[t]{2}{*}{ Safety } & Ref I6 (CC) & Appears to be safe \\
\hline & Ref I8, 19,20 (IBS) & \\
\hline \multirow[t]{2}{*}{ Diarrhea } & Ref $16(C C)$ & $3 \%-5 \%$ withdrawal rates for diarrhea \\
\hline & Ref $18,19,20$ (IBS) & \\
\hline Economic evidence & Unknown & $\begin{array}{l}\text { The drug has not yet been approved } \\
\text { by US FDA for use in constipation or IBS }\end{array}$ \\
\hline
\end{tabular}

\section{Introduction}

Irritable bowel syndrome (IBS) is a gastrointestinal disorder characterized by chronic abdominal pain and altered bowel habits in the absence of an organic cause. The prevalence of IBS in the US, based on population-based studies, is approximately $10 \%-15 \%$, and it is the most commonly diagnosed gastrointestinal condition. ${ }^{1}$ A population-based study in Europe found a similar overall prevalence of $11.5 \%{ }^{2}$ 
Patients with IBS account for upto $25 \%-50 \%$ of all referrals to gastroenterologists, ${ }^{3}$ and some studies estimate that annual direct and indirect health care costs in the US are as high as $\$ 30$ billion. $^{4}$

Patients with IBS can present in various ways, but the symptom complex of chronic abdominal pain and altered bowel habits remains the nonspecific yet primary characteristic of IBS. The abdominal pain is described as a cramping sensation, varying in intensity and with exacerbations. Patients with IBS also complain of altered bowel habits, ranging from diarrhea, constipation, alternating diarrhea and constipation, or normal bowel habits, alternating with either diarrhea and/or constipation. ${ }^{5}$

In contrast with IBS, chronic constipation is described as a combination of infrequent bowel movements, hard stools, straining during defecation, bloating, abdominal discomfort, and/or a sense of incomplete evacuation. Constipation affects between $12 \%$ and $19 \%$ of the US population and is also associated with substantial costs. ${ }^{6}$ Although there is probably a considerable overlap with IBS-C, the focus of treating functional constipation centers predominantly on improving bowel habits, whereas the approach to patients with IBS-C must encompass improving abdominal pain as well as bowel habits. This makes the treatment of IBS-C more complicated and efficacy of such treatment more difficult to measure.

Unfortunately, there are no effective and safe treatments for all patients with IBS-C or for those with chronic constipation. Laxatives can help with constipation but do not treat the abdominal discomfort in IBS-C, and use of pain modulators, such as tricyclic agents, may worsen constipation. Therefore, many patients remain dissatisfied with current available treatments.

Linaclotide is a novel peptide agonist of guanylate cyclase which is minimally absorbed, and acts by actively transporting chloride ions into the intestinal lumen through the cystic fibrosis transmembrane conductance regulator channel. Similar to all laxatives, linaclotide acts to increase stool water content and to enhance the frequency and ease of defecation by a secretory mechanism. ${ }^{7}$ This new agent has undergone clinical trials for the treatment of patients with IBS-C and chronic constipation. To date, results of these trials have been promising, and improvements in stool consistency, reduced straining, and reduced abdominal symptoms have been reported. These improvements are often seen in the first several days of drug administration with sustained effects.

\section{Pharmacokinetics}

The development of linaclotide as a novel compound was derived from the discovery of a family of cyclic guanosine-3', $5^{\prime}$-monophosphate (cGMP)-regulating peptide hormones. ${ }^{8}$ These peptides, guanylin and uroguanylin, are found in the gastrointestinal tract and are released into the intestinal lumen. Stimulation of guanylate cyclase $C$ receptors by both peptides increases concentrations of cGMP, the second messenger which (among other actions) increases intestinal secretion of water and electrolytes. ${ }^{9}$

In nature, heat-stable bacterial endotoxins produce a secretory diarrhea by stimulating cGMP, and formed the conceptual basis for the pharmacologic development of a substituted homolog of stable endotoxins. Linaclotide is a 14-amino acid peptide homolog of stable bacterial endotoxins which incorporates the three disulfide bonds of the toxin to produce maximum potency. Removal of the C-terminal tyrosine residue by carboxypeptidase A produces a 13-amino acid peptide which enhances pharmacokinetic stability by resisting proteolysis and is associated with minimal intestinal absorption. In vivo animal studies and in vitro studies in T84 human colon carcinoma cells characterized the binding of linaclotide to guanylate cyclase $\mathrm{C}$ receptors with resultant stimulation of intracellular cGMP. ${ }^{10}$

Stability of linaclotide was demonstrated by showing no degradation after incubation in simulated gastric fluid $(\mathrm{pH} 1)$, and the compound was also completely resistant to degradation by pepsin after 3 hours of incubation. Also, orally administered linaclotide was minimally absorbed in rat studies. While linaclotide stimulated significant secretion when injected into rat duodenal, jejunal, and ileal loops, increased cGMP levels were highest in the duodenum and jejunum. ${ }^{10}$

\section{Initial clinical studies}

The initial Phase I studies in 30 healthy subjects were published in 2005 and established that linaclotide was safe and well tolerated in single oral doses of up to $3000 \mu \mathrm{g}$. Drug administration elicited a decrease in stool consistency as measured on the Bristol Stool Form Scale with an increase in stool weight. ${ }^{11}$ In a subsequent multiple ascending-dose Phase I trial of linaclotide in 48 healthy subjects, oral doses of $30,100,300$, or $1000 \mu \mathrm{g}$ were administered once daily for 7 days. Linaclotide at all doses was again well tolerated, with a statistically significant increase in stool frequency and weight from baseline Bristol Stool Form Scale scores at the $30 \mu \mathrm{g}, 300 \mu \mathrm{g}$, and $1000 \mu \mathrm{g}$ doses. Mean ease of stool 
passage increased significantly from baseline in the $1000 \mu \mathrm{g}$ group. ${ }^{12}$

\section{Studies in chronic functional constipation}

The efficacy of linaclotide in patients with chronic constipation was initially evaluated in a randomized, doubleblind, placebo-controlled pilot study. Forty-two patients with chronic constipation were randomized to linaclotide $(100,300$, or $1000 \mu \mathrm{g})$ or placebo once daily for 14 days to evaluate the safety, tolerability, and efficacy of the drug. A significant increase in the frequency of spontaneous bowel movements occurred with the $100 \mu \mathrm{g}$ dose compared with placebo (change 6.18 versus 2.76 for placebo, $P=0.047$ ). Frequency of complete and spontaneous bowel movements (CSBMs) also increased, with mean changes of 2.16, 2.90, and 3.19 for the 100,300 and $1000 \mu \mathrm{g}$ doses, respectively, versus 1.30 for placebo. The authors considered CSBM to be a more clinically meaningful endpoint than spontaneous bowel movement because epidemiologic surveys have found that many constipated persons do not qualify for constipation by Rome II criteria based on stool frequency alone. This is because most constipated persons complain of defecation difficulties and/or a sense of incomplete evacuation. ${ }^{13}$ Stool consistency also improved in a dose-related manner in all three drug groups, with a statistically significant increase with the $1000 \mu \mathrm{g}$ dose versus placebo (change 2.58 versus 0.43 for placebo, $P=0.014)$. Straining improved in all groups, with the greatest improvement with the higher doses (change 1.33 and 1.51 for $300 \mu \mathrm{g}$ and $1000 \mu \mathrm{g}$, respectively, versus 0.36 for placebo). Dose-related improvements were also seen in abdominal discomfort (mean scores decreased from baseline by $-0.58,-0.76$, and -0.85 for linaclotide 100,300 , and $1000 \mu \mathrm{g}$, respectively, versus -0.16 for placebo), overall relief, and severity of constipation. The effect on bowel habits occurred within the first few days of treatment and overall relief of constipation occurred within the first week. The improvement scores regressed towards baseline after the drug was stopped. Because there was no worsening compared with baseline, the authors concluded that there was no evidence of a rebound effect. ${ }^{14}$

A subsequent dose-ranging study of chronic constipation was done with larger numbers of patients and a longer duration of treatment. In this multicenter, double-blind trial, 310 patients with chronic constipation, as defined by Rome II criteria, were randomized into groups given 75, 150, 300, or $600 \mu \mathrm{g}$ oral linaclotide or placebo once daily for 4 weeks.
Rescue medications were allowed, including oral bisacodyl (up to $15 \mathrm{mg}$ daily), Fleets enema, or bisacodyl suppositories, but no more than two rescue medications were allowed in the pretreatment period. Mean increases in frequency of spontaneous bowel movement exhibited a linear dose response with increases of 2.6, 3.3, 3.6, and 4.3 for doses of $75,150,300$, and $600 \mu \mathrm{g}$, respectively, compared with 1.5 for placebo $(P<0.05)$. Patients receiving drug were more likely to have a spontaneous bowel movement within the first 24 hours $(50.8 \%, 55.4 \%, 54.8 \%$, and $75.8 \%$, respectively, for the four doses) compared with placebo $(36.8 \%, P<0.05)$. The median time to first spontaneous bowel movement was 24.0, 21.9, 23.1, and 13.0 hours for the four doses versus 32.6 hours for placebo $(P=0.0005$ for overall log-rank test). Similar changes were seen for mean weekly CSBM frequency. Improvement in overall stool consistency was also dose-related, as was overall straining. Bowel habits returned to baseline patterns during the post-treatment period, suggesting no rebound worsening of constipation. The percentage of patients who reported a decrease in the abdominal discomfort score (defined as $\geq 0.5$ for 3 of 4 weeks) ranged from $27 \%$ to $32 \%$ for the four linaclotide doses versus $12 \%$ for placebo $(P<0.05$ for each dose). Similarly, the percentage of patients who reported a decrease in the bloating score (defined as $\geq 0.5$ for 3 of 4 weeks) ranged from $29 \%$ to $39 \%$ for linaclotide versus $12 \%$ for placebo $(P<0.05)$. All three global measures, including constipation severity, adequate relief of constipation, and relief of constipation, improved in dose-dependent manner. Of note, there was no significant change in rescue medication use between the placebo and linaclotide groups. ${ }^{15}$

In 2011, the results of two Phase III trials in chronic constipation were reported. Two randomized, 12-week, multicenter, double-blind, parallel-group, placebo-controlled trials were performed at 204 clinical centers in the US and at eight clinical centers in Canada. The trials were identical except that one trial included a 4-week period of randomized withdrawal at the conclusion of the 12 -week treatment period. In a ratio of $1: 1: 1$, patients were randomly given $145 \mu \mathrm{g}$ or $290 \mu \mathrm{g}$ of linaclotide, or placebo. After completing the treatment period, patients in one trial who had received linaclotide during the preceding treatment period were randomly assigned to either the same linaclotide dose or placebo, whereas patients who had received placebo during the treatment period were given $290 \mu \mathrm{g}$ of linaclotide for a 4-week period.

Eligible patients who met the criteria for chronic constipation reported fewer than three spontaneous bowel movements 
per week (without laxatives, enemas, or suppositories in the preceding 24 hours) and straining, lumpy, or hard stools or a sensation of incomplete evacuation for more than $25 \%$ of bowel movements for at least 12 weeks within the preceding 12 months. In addition, during the 14-day baseline period, patients had to report an average of fewer than six spontaneous bowel movements and fewer than three CSBMs per week. The primary endpoint of both trials was defined as both three or more CSBMs per week and an increase of at least one CSBM per week from baseline for at least $75 \%$ of the weeks of the treatment period. Secondary endpoints included stool frequency, stool consistency, severity of straining, abdominal discomfort, bloating, and constipation severity. Additional endpoints such as constipation relief, satisfaction with treatment, the likelihood of treatment continuation, and health-related quality of life were determined.

A total of 1272 patients (642 in trial 303 and 630 patients in trial 01) were included in the intention-to-treat analysis; rates of compliance during the treatment period were over $86 \%$. In the two trials, $21.2 \%$ and $16.0 \%$ of the patients who received the $145 \mu \mathrm{g}$ dose and $19.4 \%$ and $21.3 \%$ of the patients who received the $290 \mu \mathrm{g}$ dose, respectively, met the primary endpoint versus $3.3 \%$ and $6.0 \%$ with placebo $(P<0.01$ for each dose). In both trials, differences in overall response rates between the two linaclotide doses were not statistically significant. For all secondary endpoints, linaclotide-treated patients had significant improvements versus placebo. Weekly CSBM rates increased significantly with linaclotide in the first week and were maintained throughout the 12-week period. In both trials, scores for constipation relief, treatment satisfaction, and treatment continuation were significantly greater in both treatment groups than in the placebo group. At week 12, $44.9 \%$ and $42.2 \%$ of respective patients who received $145 \mu \mathrm{g}$ and $35.5 \%$ and $46.8 \%$ of those who received $290 \mu \mathrm{g}$ of linaclotide had improved by one point or more from baseline in overall Patient Assessment of Constipation Quality of Life score, compared with $18.7 \%$ and $27.8 \%$ who received placebo $(P<0.01)$. In trial 303, which included an additional 4 weeks, patients who continued to take linaclotide and those who were switched from placebo to linaclotide had sustained increases in the frequency of CSBMs similar to levels reported during the treatment period, whereas patients who switched from linaclotide to placebo had a decreased frequency of CSBMs. ${ }^{16}$

\section{Studies in IBS-C}

The first Phase IIA, randomized, double-blind, placebocontrolled single-site study evaluated the effects of oral linaclotide $100 \mu \mathrm{g}$ and $1000 \mu \mathrm{g}$ once daily for 5 days in 36 women with IBS-C. The primary endpoint was the effect on ascending colon emptying and colonic transit as determined by scintigraphy. There were no demonstrable effects of linaclotide on gastric emptying or colonic filling at 6 hours, the latter being a marker for small intestine transit time. However, there was significant acceleration of ascending colon emptying, but only with $1000 \mu \mathrm{g}$ compared with placebo $(P=0.004)$. The acceleration of ascending colon transit may have been due to decreased colon fluid absorption, because there is a high capacity of fluid absorption in this part of the colon. Acceleration of overall colonic transit occurred at 48 hours $(P=0.02)$, but not at 24 hours. As with ascending colon emptying, the geometric center at 48 hours was significantly faster only with $1000 \mu \mathrm{g}(P=0.01)$. As determined by daily stool diaries, linaclotide shortened the time to first bowel movement $(P=0.013)$, increased stool frequency $(P=0.037)$, decreased stool consistency $(P<0.001)$, and improved ease of stool passage $(P<0.001)$. There was no significant effect on sense of complete evacuation. ${ }^{17}$

In a subsequent Phase IIB trial, Johnston et al performed a randomized, double-blind, multicenter, placebo-controlled

Table I Rome III criteria for functional constipation and IBS- $\mathrm{C}^{5}$

\begin{tabular}{ll}
\hline Functional constipation & IBS-C \\
\hline Loose stools not present and insufficient criteria for IBS & $\begin{array}{l}\text { Recurrent abdominal discomfort } \geq 3 \text { days per month for } \geq 3 \text { months } \\
\text { associated with } \geq 2 \text { of the following } \\
\text { Improvement with defecation }\end{array}$ \\
$\begin{array}{l}\text { Symptoms for }>6 \text { months and at least two of the following symptoms } \\
\text { for }>25 \% \text { of defecations during past } 3 \text { months }\end{array}$ & $\begin{array}{l}\text { Onset associated with change in frequency in stool } \\
\text { Straining }\end{array}$ \\
$\begin{array}{l}\text { Lumpy or hard stools } \\
\text { Sensation of incomplete evacuation }\end{array}$ & $<25 \%$ of bowel movements were loose stools \\
Sensation of anorectal obstruction/blockage & \\
Manual maneuvers to facilitate defecations & \\
$<3$ defecations/week &
\end{tabular}

Abbreviations: IBS, irritable bowel syndrome; IBS-C, IBS in which constipation is the main gastrointestinal symptom. 


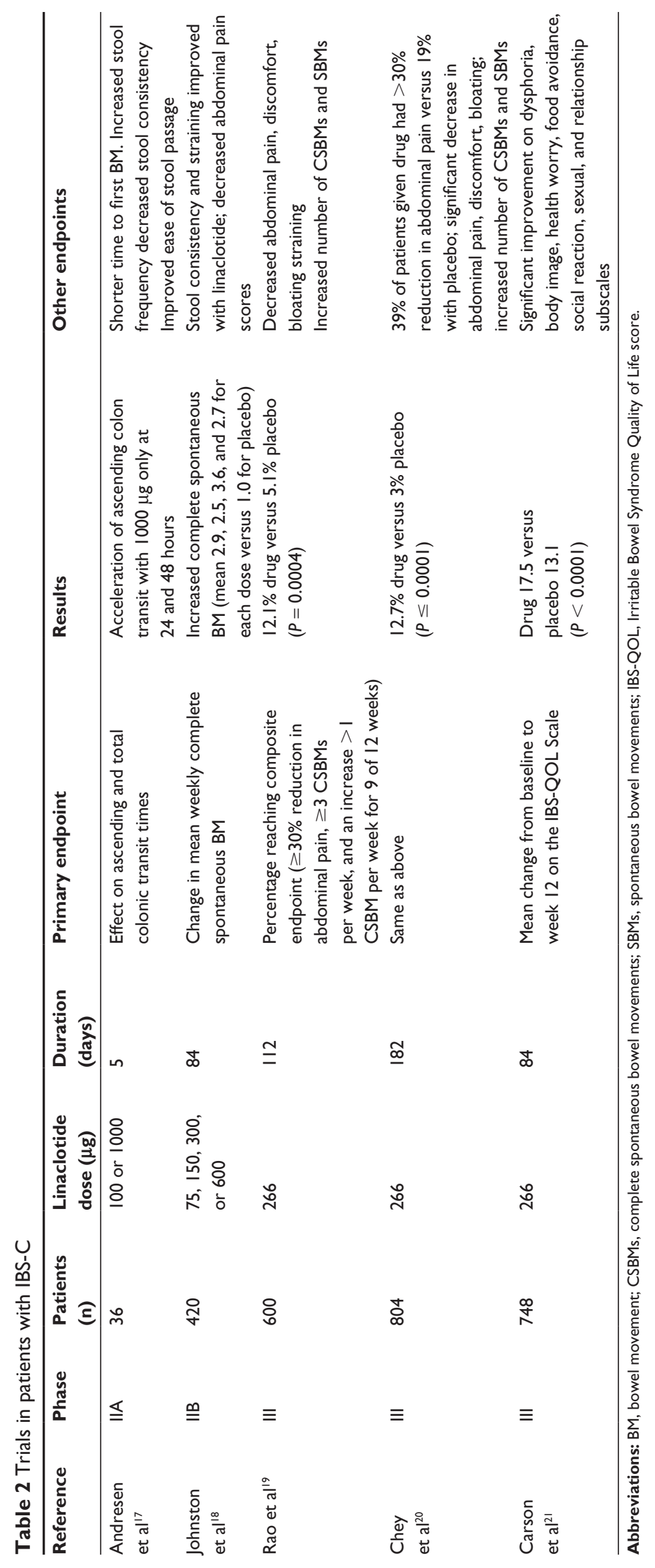




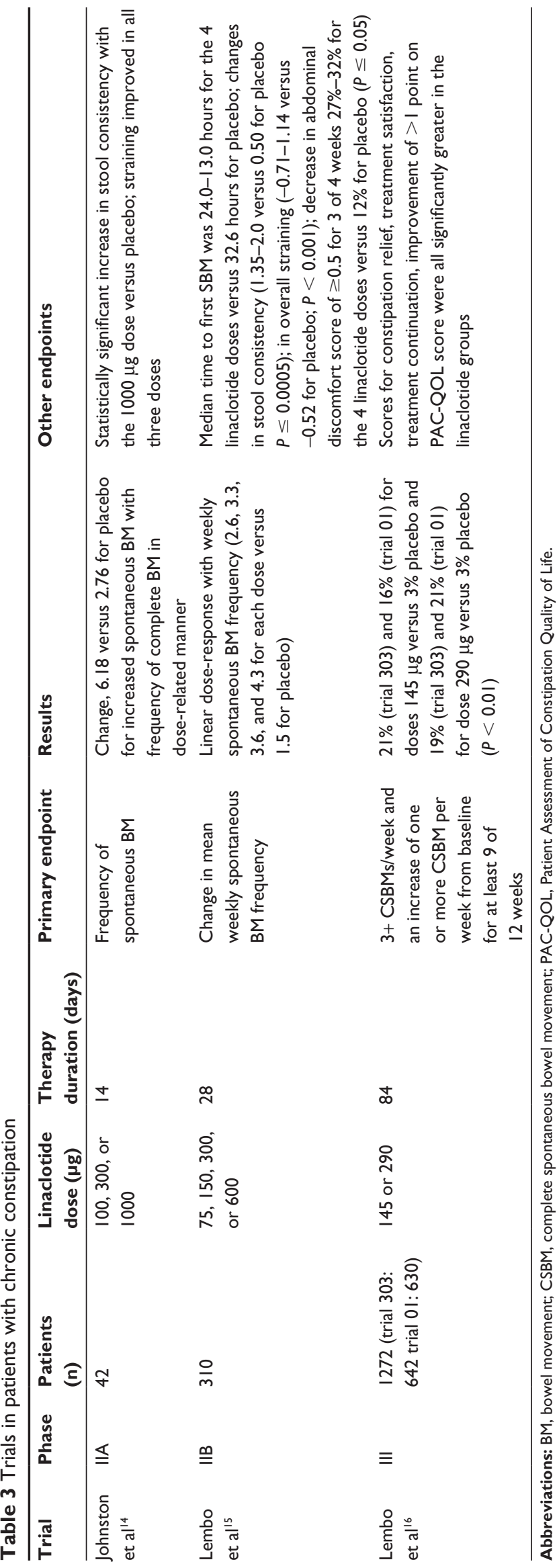

study of 420 patients with IBS-C using oral linaclotide doses of $75,150,300$, or $600 \mu \mathrm{g}$ or placebo once daily for 12 weeks. With all doses, there were mean increases of daily stool frequency ranging from 2.5 to 3.6 versus 1.0 for placebo $(P<0.01)$ which were evident within 24 hours of treatment. Stool consistency and straining also improved with linaclotide compared with placebo $(P<0.001)$, and decreases in abdominal pain scores were significantly greater for all doses, with mean changes of -0.7 to -0.9 versus -0.5 for placebo on a scale of $1-5(P<0.05)$. Improvement in pain occurred within the first week and persisted throughout the study; those who reported "severe" or "very severe" abdominal pain for at least $50 \%$ of the pretreatment period had the greatest reduction of abdominal pain. Patient-reported satisfaction to relief of symptoms IBS symptoms was greater with all except the $75 \mu \mathrm{g}$ dose. ${ }^{18}$

A double-blind randomized controlled Phase III trial evaluated the efficacy and safety of linaclotide $266 \mu \mathrm{g}$ $(n=405)$ versus placebo $(n=395)$ for 12 weeks. An additional 4 weeks after the initial 12-week treatment period were included to assess the effects of therapy withdrawal; during this time, patients previously randomized to placebo received linaclotide, and patients who originally received linaclotide were randomly assigned to either linaclotide or placebo. After 12 weeks, the percentage of patients meeting the composite endpoint was significantly greater with linaclotide compared with placebo (12.1 versus 5.1, respectively; $P=0.0004$ ). All secondary endpoints (abdominal pain/discomfort, bloating, straining, stool consistency, and number of CSBMs and spontaneous bowel movements per week) demonstrated statistically significant improvements with drug compared with placebo. Abdominal pain, discomfort, and bloating had a mean change from baseline of approximately -2 (rated on a 10-point scale), compared with -1.1 with placebo $(P<0.0001)$, and straining -1.3 (rated on a five-point scale) compared with -0.7 with placebo $(P<0.0001)$. The number of weekly CSBMs and spontaneous bowel movements increased to 2.3 and 3.9, respectively, compared with 0.7 and 1.1 with placebo $(P<0.0001)$. After the initial 12 weeks, patients originally given linaclotide and who remained on linaclotide showed continued improvements, but a return of symptoms was seen in those patients who were switched to placebo therapy. On the other hand, patients given placebo showed improvement in abdominal pain in just one week after being switched to linaclotide. ${ }^{19}$

In another double-blind Phase III trial, the long-term use of linaclotide was assessed, in which patients were randomized to receive either linaclotide $266 \mu \mathrm{g}(\mathrm{n}=401)$ or placebo 
$(n=403)$ for a period of 26 weeks. The primary endpoint of the trial was a composite endpoint identical to the previous study. In total, $12.7 \%$ of patients randomized to linaclotide demonstrated significant improvement in the primary endpoint compared with only $3 \%$ given placebo $(P \leq 0.0001)$; these improvements were sustained throughout the 26 weeks of the trial. Approximately $39 \%$ of patients given linaclotide had a $>30 \%$ reduction in abdominal pain as compared with $19 \%$ for placebo. A significant decrease in abdominal pain, discomfort, and bloating of -1.9 (rated on a 10-point scale) occurred with linaclotide versus -1.1 with placebo at 12 weeks ( $P \leq 0.0001$ for all measures), and a further decrease of -2.2 in the linaclotide group compared with -1.2 with placebo was seen at 26 weeks. At 12 and 26 weeks, the number of weekly CSBMs and spontaneous bowel movements increased to 2.2 and 4.0 for linaclotide-treated patients, compared with 0.7 and 1.2 for placebo-treated patients. ${ }^{20}$

A randomized, double-blind, placebo-controlled, Phase III trial in IBS-C studied the overall quality of life scores and several subset scores of the IBS-Quality of Life questionnaire. These scores improved in patients receiving linaclotide compared with placebo over 12 weeks. A mean change of 17.45 in overall quality of life scores versus 13.1 with placebo $(P<0.0001)$ including significant improvements on dysphoria, body image, health worry, food avoidance, social reaction, sexual, and relationship subscales $(P<0.0001) .^{21}$

\section{Safety and tolerability}

Both Phase I trials showed no significant adverse effects and no differences between placebo-treated and linaclotidetreated subjects. The medication was well tolerated at all dose levels, and with no systemic exposure detected. ${ }^{11,12}$

In the first Phase II trial for chronic constipation, there were 22 mild or moderate adverse effects among the 42 patients, all but one occurring in the linaclotide-treated patients. The diarrhea in four patients was not dosedependent. Two patients discontinued the medication due to rash and moderate diarrhea. ${ }^{14}$ No clinically significant adverse effects were reported in the second Phase II trial for chronic constipation; $34 \%$ of patients receiving linaclotide had an adverse effect compared with $32 \%$ receiving placebo; this was slightly higher with the $600 \mu \mathrm{g}$ dose (38\%) compared with the other groups. Not unexpectedly, diarrhea was the most common gastrointestinal adverse effect, ranging from $5 \%$ to $14 \%$ of patients receiving from $75 \mu \mathrm{g}$ to $600 \mu \mathrm{g}$ versus $3 \%$ of patients receiving placebo. Half of all reports of diarrhea occurred within 2 days of starting the study medication, and most were mild or moderate. Only two adverse effects were graded as severe diarrhea and both occurred with the highest dose. ${ }^{15}$

As expected, the most common adverse effect in both Phase III trials for chronic constipation was diarrhea. There was a single death which was attributed to an overdose of fentanyl. Serious adverse effects were reported in $1.4 \%$ of patients receiving $145 \mu \mathrm{g}$ of linaclotide, $2.6 \%$ of patients receiving $290 \mu \mathrm{g}$ of linaclotide, and $2.1 \%$ of patients receiving placebo. Due primarily to diarrhea, discontinuation of treatment during the 12 weeks was higher among the linaclotide-treated patients, occurring in $7.9 \%$ of patients who received $145 \mu \mathrm{g}$ and in $7.3 \%$ of those who received $290 \mu \mathrm{g}$, compared with $4.2 \%$ receiving placebo. The first occurrence of diarrhea for many patients occurred during the initial 2 weeks of therapy; 13 of the 852 patients $(1.5 \%)$ who received linaclotide had severe diarrhea, versus only one of 424 patients $(0.2 \%)$ on placebo. There were no clinically significant differences in other laboratory parameters, electrocardiographic results, or vital signs between the drug and placebo groups. ${ }^{16}$

In the initial Phase II trial in IBS-C, linaclotide was safe and well tolerated at $1000 \mu \mathrm{g}$ but the duration of treatment was brief. ${ }^{17}$ In the more recent trial for IBS-C, adverse effects occurred in 3\% of all linaclotide-treated patients; diarrhea was the most common adverse effect and was more frequent with higher doses $(18 \%$ of patients receiving the $600 \mu \mathrm{g}$ dose versus $1.2 \%$ in placebo). Nine of the diarrhea adverse effects were graded as severe, but there were no clinical consequences, such as dehydration or electrolyte imbalances. The only severe adverse effect was fecal impaction which occurred from withholding the study medication, but this resolved with treatment. ${ }^{18}$ In the Phase III trials, the most common adverse effect again was diarrhea, but it was mostly well tolerated.

\section{Discussion}

The treatment of IBS-C and chronic constipation continue to be problematic for many patients and their health care providers. The goals of therapy in each of these disorders overlap to some degree, but there are additional issues in the IBS-C population.

The goal of treatment for chronic constipation is to relieve altered bowel habits, i.e. to increase (complete) spontaneous bowel movements and to have a sense of complete evacuation. The clinical effectiveness of linaclotide versus placebo for chronic constipation has been demonstrated in a series of clinical trials, culminating in the recently published two large 
Phase III trials. ${ }^{16}$ Using the number of CSBMs as a primary endpoint, $21.2 \%$ and $16.0 \%$ of patients who received the $145 \mu \mathrm{g}$ dose of linaclotide, and $19.4 \%$ and $21.3 \%$ of the patients who received the $290 \mu \mathrm{g}$ dose of linaclotide, respectively, in the dual trials, met the primary endpoint. Although this is clinically significant, it is worthwhile to emphasize that only a minority of treated patients met the primary endpoint. Furthermore, it is not established that this drug would be more effective than widely available osmotic laxatives, such as bisacodyl ${ }^{22}$ and polyethylene glycol, ${ }^{23}$ the efficacy of which versus placebo has been previously established in several randomized, placebo-controlled trials. It seems important to conduct head-to-head comparison trials with these agents in the future and also to determine if linaclotide is more efficacious in certain constipated individuals than are currently available laxatives. Another point to emphasize is that linaclotide is unlikely to benefit in patients with pelvic floor dyssynergia, another cause of chronic constipation that responds poorly to laxatives. Polyethylene glycol and bisacodyl are widely and relatively inexpensive and likely will continue to be first-line agents for constipation. Therefore, the appropriate indication for linaclotide is likely to be as a second-tier agent where cost, efficacy, and side effects compared with other second-tier agents such as lubiprostone will play important roles.

In patients with IBS-C, simply increasing the frequency of spontaneous bowel movements is insufficient, as treatment also needs to target the abdominal discomfort often exhibited by these patients. In both Phase II and Phase III trials, the efficacy of linaclotide has been promising, with significant improvement in stool consistency and straining as well as decreases in abdominal pain scores versus placebo. Its ability to target many of the symptoms of irritable bowel syndrome with relatively few adverse effects makes it a potentially attractive medication for this subgroup of IBS patients. Nevertheless, it has proven effective in only a minority of patients, with improvement over placebo of approximately $10 \%$. IBS is a heterogeneous disorder and not likely to respond to monotherapy in many cases. The precise role of linaclotide in IBS-C remains to be established.

In addition to their efficacy in past trials, linaclotide has been well tolerated with similar adverse effects to placebo. Not surprisingly, the most common side effect has been diarrhea, but very few cases of diarrhea have been severe. This is in contrast with other agents for IBS-C, such as tegaserod, ${ }^{24}$ with its (admittedly tiny) risks of cardiovascular events, and lubiprostone, ${ }^{25}$ with its more frequent side effects of nausea and headaches.
In conclusion, linaclotide has certainly been shown to be effective in chronic constipation and IBS-C in the recently published Phase II and Phase III trials. Future studies are needed in patients with chronic constipation to compare this new agent with widely available and less expensive agents, such as polyethylene glycol and bisacodyl. Linaclotide is an attractive drug because of its apparent ability to alleviate symptoms of irritable bowel syndrome with a single daily dose. In addition, it is well tolerated and has been proven to be a safe medication to use. At the time of writing, the US Food and Drug Administration has accepted the new drug application for linaclotide for review in chronic constipation and IBS-C.

\section{Disclosure}

The authors report no conflicts of interest in this work and received no payment for preparing this manuscript.

\section{References}

1. Thompson WG, Irvine EJ, Pare P, et al. Functional gastrointestinal disorders in Canada: first population-based survey using Rome II criteria with suggestions for improving the questionnaire. Dig Dis Sci. 2002;47:225-235.

2. Hungin AP, Whorwell PJ, Tack J, Mearin F. The prevalence, patterns and impact of irritable bowel syndrome: an international survey of 40,000 subjects. Aliment Pharmacol Ther. 2003;17:643-650.

3. Everhart JE, Renault PF. Irritable bowel syndrome in office-based practice in the United States. Gastroenterology. 1991;100:998-1005.

4. Sandler RS, Everhart JE, Donowitz M, et al. The burden of selected digestive diseases in the United States. Gastroenterology. 2002;122:1500-1511.

5. Longstreth GF, Thompson WG, Chey WD, et al. Functional bowel disorders. Gastroenterology. 2006;130:1480-1491.

6. Higgins PD, Johanson JF. Epidemiology of constipation in North America: a systematic review. Am J Gastroenterol. 2004;99:750-759.

7. Bharucha AE, Waldman SA. Taking a lesson from microbial diarrheagenesis in the management of chronic constipation. Gastroenterology. 2010;138:813-825.

8. Bryant AP, Busby RW, Bartolini WP, et al. Linaclotide is a potent and selective guanylate cyclase $\mathrm{C}$ agonist that elicits pharmacological effects locally in the gastrointestinal tract. Life Sci. 2010;8:760-765.

9. Lucas KA, Pitari GM, Kazerounian S, et al. Guanylyl cyclases and signaling by cyclic GMP. Pharmacol Rev. 2000;52:375-414.

10. Busby RW, Bryant AP, Bartolini WP, et al. Linaclotide, through activation of guanylate cyclase $\mathrm{C}$, acts locally in the gastrointestinal tract to elicit enhanced intestinal secretion and transit. Eur J Pharm. 2010;649: 328-335.

11. Currie MG, Kurtz CB, Mahajan-Miklos S, et al. Effects of a single dose administration of MD-1100 on safety, tolerability, exposure, and stool consistency in healthy subjects. Am J Gastroenterol. 2005;100:S328.

12. Kurtz CB, Fitch D, Busby RW, et al. Effects of multidose administration of MD-1100 on safety, tolerability, exposure, and pharmacodynamics in healthy subjects. Gastroenterology. 2006;130 Suppl 2:A26.

13. Stewart WF, Liberman JN, Sandler RS, et al. Epidemiology of constipation (EPOC) study in the United States: relation of clinical subtypes to sociodemographic tures. Am J Gastroenterol. 1994;94:3530-3540.

14. Johnston JM, Kurtz CB, Drossman DA, et al. Pilot study on the effects of linaclotide in patients with chronic constipation. Am J Gastroenterol. 2009;104:125-132. 
15. Lembo AJ, Johnston JM, MacDougall JE, et al. Efficacy of linaclotide for patients with chronic constipation. Gastroenterology. 2010;138: 886-895.

16. Lembo AJ, Schneier H, Shiff S, et al. Two randomized trials of linaclotide for chronic constipation. $N$ Engl J Med. 2011;365:527-536.

17. Andresen V, Camilleri M, Busciglio IA, et al. Effect of 5 days of linaclotide on transit and bowel function in females with constipationpredominant irritable bowel syndrome. Gastroenterology. 2007;133: 761-768.

18. Johnston JM, Kurtz CB, MacDougall JE, et al. Linaclotide improves abdominal pain and bowel habits in a Phase IIb study of patients with irritable bowel syndrome. Gastroenterology. 2010;139:1877-1886.

19. Rao S, Lembo A, Shiff SJ, et al. Efficacy and safety of once daily linaclotide in patients with irritable bowel syndrome with constipation: a 12-week, randomized, double-blind, placebo-controlled Phase 3 trial followed by a 4-week randomized withdrawal period. Gastroenterology. 2011;140:S138.

20. Chey WD, Lembo A, MacDougall JE, et al. Efficacy and safety of once-daily linaclotide administered orally for 26 weeks in patients with IBS-C: results from a randomized, double-blind, placebo-controlled Phase 3 trial. Gastroenterology. 2011;140:S135.
21. Carson R, Tourkodimitris S, Lewis BE, Johnston JM. Effect of linaclotide on quality of life in adults with irritable bowel syndrome with constipation: pooled results from two randomized, double-blind, placebo-controlled Phase 3 trials. Gastroenterology. 2011:140-151.

22. Kamm MA, Muller-Lissner S, Wald A, et al. Oral bisacodyl is effective and well-tolerated in patients with chronic constipation. Clin Gastroenterol Hepatol. 2011;9:577-583.

23. DiPalma JA, Cleveland MV, McGowan J, Herrera JL. A randomized, multicenter, placebo-controlled trial of polyethylene glycol laxative for chronic treatment of chronic constipation. Am J Gastroenterol. 2007;102:1436-1441.

24. Al-Judaibi B, Chande N, Gregor JC. Safety and efficacy of tegaserod therapy in patients with irritable bowel syndrome or chronic constipation. Can J Clin Pharmacol. 2010;17:e194-e200.

25. Ambizas EM, Ginzburg R. Lubiprostone: a chloride channel activator for treatment of chronic constipation. Ann Pharmacother. 2007;41: 957-964.

\section{Core Evidence}

\section{Publish your work in this journal}

Core Evidence is an international, peer-reviewed open-access journal evaluating the evidence underlying the potential place in therapy of drugs throughout their development lifecycle from preclinical to postlaunch. The focus of each review is to evaluate the case for a new drug or class in outcome terms in specific indications and patient groups.

\section{Dovepress}

The manuscript management system is completely online and includes a very quick and fair peer-review system, which is all easy to use. Visit http://www.dovepress.com/testimonials.php to read real quotes from published authors. 